\title{
Effect of Vegetable Commercialization on Food Safety
}

\author{
Mbiti Job M'ithibutu ${ }^{1 *}$, Elisha Otieno Gogo ${ }^{2}$, Fikirini Lugogo Mangale ${ }^{3}$, Gregory Baker ${ }^{4}$ \\ ${ }^{1}$ School of Agricultural Sciences and Agribusiness Pwani University, Kenya \\ ${ }^{*}$ Corresponding author's email: jobithibu [AT] gmail.com \\ ${ }^{2}$ School of Agricultural Sciences and Agribusiness Pwani University, Kenya \\ Email: e.gogo [AT] pu.ac.ke \\ ${ }^{3}$ School of Business Management and Economics Pwani University, Kenya \\ Email: f.mangale [AT] pu.ac.ke \\ ${ }^{4}$ Department of Management and Entrepreneurship Santa Clara University, USA \\ Email: gbaker [AT] scu.edu
}

\begin{abstract}
The commercialization of fresh vegetables is crucial in enhancing revenues from commercial vegetable farming and ensuring reliable supply of high-quality produce for consumers. However, this is only guaranteed under ethical application of agrochemicals beyond which can lead in a more pronounced public health as well as environmental hazards. The present paper sought to examine the influence of commercialization on food safety. Vegetable samples weighing between 1 to $2 \mathrm{~kg}$ were purchased from randomly selected producers in two major producing counties (Kiambu and Kirinyaga) in Kenya. All samples were freeze-dried and stored in an ice chess box, to minimize contamination. Then the samples were labeled, and transported to the laboratory for processing and testing. All approved samples were subjected to the QuEChERS preparation method for pesticides and quantified using gas chromatography equipped with mass spectrometry (GC-MS). Lab results tested positive for 13 problematic pesticides including known carcinogens and highly hazardous agrochemicals such as Malathion, chlorothalonil and chlorpyrifos. The most common agrochemical was carbofuran (67\%) in terms of insecticide. For the case of fungicides, the most common was mancozeb (60\%) and metalaxyl (58\%). Food safety issues are caused mainly by not observing preharvest intervals, excessive application of chemicals and use of illegal agrochemicals. Chemical residues in food mainly results in carcinogenic diseases (43 to 49\%), stomach related problems (15 to 19\%), eye related problems (10 to 15\%), and skin related problems (11 to 14\%) and breathing difficulties (10 to 12\%). This study demonstrates that there is a problem of agrochemical use and food safety concerns and kale and tomato value chain.
\end{abstract}

Keywords--- Commercialization, Agrochemicals, Chemical residues, Producers, Consumers

\section{INTRODUCTION}

In order to address the escalating food demand, global community need choose whether to expand the current agricultural area to increase total production (extensification) or to concentrate on increasing yields of the existing agricultural land (intensification). On one hand, the former option would result to encroaching and altering of vital ecosystems and injuring of community livelihoods. On the other hand, the later would warrant use of productivity enhancers which would also contribute to alteration of the ecosystem (soil structure, organism diversity among others) and safety concerns. Considering that extensification is highly detrimental over a bigger area and would eventually necessitate upscaling to intensification over time, the latter has been favored across the world. Intensification in under-yielding nations (especially poor countries) has been further touted for lower environmental effects such as clearing of approximately 0.2 billion ha of land, $\mathrm{CO}_{2}-\mathrm{C}$ equivalent greenhouse gas emissions and global $\mathrm{N}$ use compared to extensification which would require clearing of $\sim 1$ billion ha, $\sim 3 \mathrm{Gt} \mathrm{y}^{-1}$ emissions and $\mathrm{N}$ use of $\sim 250 \mathrm{Mt} \mathrm{y}^{-1}$ (Tilman et al., 2011).

Agricultural commercialization presents an opportunity to produce more food for the bulging population, but ethical issues associated with the use of external inputs arise thus contributing to food safety risks (Kenmore et al., 2004). Most often in agricultural commercialization, food safety risks arise at the production level due to improper use of external inputs in terms of quantities, formulations, type of agrochemical and time of application, resulting to chemical residues in food (Prabhakar et al., 2010). Researchers such as Waltner-Toews and Lang (2000) have attributed food safety risk to the technique in which resources especially substances have been utilized in production as well as distribution of food. In as much as the threat to food security is global, it is more prevalent in the developing countries due to gaps on food safety regulations and enforcement (Unnevehr, 2000). As a result, the World Health Organization (WHO, 2014) estimates 2 million deaths annually in developing world to be caused by diseases resulting from the consumption of unsafe food and water. 
Recently, food safety concerns have been on the rise in international trade circles especially with regard to fresh food products such as vegetables. The concerns are interlinked with the effects emanating with the increasing use of agrochemicals commonly referred to as the "cocktail effect" which is the resultant interaction impact of various chemical residues (Mabe et al., 2017; Ahoudi et al., 2018). As a result of this trend, developed countries have increasingly revised their chemical residue standards thereby introducing stringent regulations for fresh produce exports from developing countries (Okello \& Swinton, 2010) and boosted in-country monitoring systems.

In Kenya, use of banned pesticides and misuse agrochemicals have been reported in horticultural production contributing to rejections of fresh produce in export markets due to non-compliance to the set maximum residue levels (MRLs) (Nguetti et al., 2018; Okado, 2001). Food safety concerns are higher with the regenerative category of fresh vegetable. After they are harvested, they regenerate again and thereby necessitating use of agrochemicals to boost the development of the regenerating parts, for instance, tomato (Solanum lycopersicum L.) as well as kales (Brassica oleracea L. var. acephala). The regenerative aspect narrows down the time it takes from spraying to maturity and harvesting (closes down the harvesting-spraying-maturity-harvesting gap) thus increasing the food safety risk associated with continuous application of agrochemicals throughout its life. This category of vegetables is mainly consumed domestically where there is lack of coordinated food safety management system for fresh produce thereby leaving the local consumers' safety at the hands of profit-oriented producers.

A report by European Union (EU) shows that Kenya has been on high alert by officials who are flashing out products rejected by external markets such as Europe due to high residual levels of chemicals and heavy metals consequently unfit for humans and environment (Gitonga et al., 2010). In essence, European Union has put Kenya on notice as being one of the many nations with increased maximum residual levels (MRLs). The report also indicates that a total of 11 domestic exporting firms have remained in the meantime banned for failing to meet these standards (ibid).

Kenya Plant Health Inspectorate Services (KEPHIS) have correspondingly remained active in the fight to make sure that consumers are safe. Despite their efforts, produce which are banned in the external markets are being dumped in the domestic markets where scrutiny and alerts are not as strict. As per the Consumer Federation of Kenya (COFEK), vegetables and fruits in the local markets are worryingly loaded with metals and harmful pesticides (Inonda et al., 2015). In other cases, counterfeit pesticides and those rejected in the external market are in use, particularly for products in the domestic market.

With the increasing levels of commercialization and differing production regimes, the export markets are keen on production practices and subject producers to rigorous pre-inspection controls from production, harvesting to post harvest handling in order to guarantee food safety and quality to their target consumers. Unlike the export markets, domestic markets are not keen on what is offloaded in the markets because the local food systems set-up have been keen on complying with export standards whereas food (fresh vegetable) safety for domestic consumers has largely been left at the mercy of profit oriented primary producers (Gitonga et al., 2010). There have also been indications that fresh produce that is rejected for export is diverted into the domestic food supply chains. In addition, the country's consumer welfare watchdog has not been outspoken in order to initiate debate and policy action in relation to agribusiness ethics compliance by fresh food producers (Muriithi \& Matz, 2014; Rahman et al., 2021).

Majority of farmers either lack the knowledge to safely use agrochemicals or deliberately abuse them towards perceived objectives. Therefore, they do not observe pre-harvest intervals. Some apply excess chemicals than recommended. This has led to rejection of fresh commodities especially for export market. High chemical residue has also led to increased carcinogenic disease incidences on consumers. Scientists have increasingly linked global mortality to consumption of unsafe fruit and vegetable (Trichopoulou et al., 2003; Schneider et al., 2007; Agudo et al., 2007; Nicklett et al., 2012). Oyebode et al. (2014) established an association among fruit and vegetable consumption as well as cancer and heart illness mortalities.

Tomatoes as well as kales (sukuma wiki) contain higher pesticides residues as they are more heavily treated than other fruits and vegetables (Oyugi, 2013). It is also true that there is no formally laid out mechanism in use for monitoring agrochemicals at the farm level in developing countries as well as the quality of fresh food offloaded to the domestic markets. The major question is, 'is the Kenya vegetable domestic producer keen on agribusiness ethics? Is the consumer safe? In order to answer these fundamental questions, this paper sought to evaluate the impact of vegetable commercialization on agribusiness regulatory compliance and food safety in Kenya. 


\section{MATERIALS AND METHODS}

\subsection{Location of the Study}

The study was conducted in Kirinyaga, Kiambu and Nairobi counties of Kenya. According to D'Alessandro et al. (2019), Kirinyaga County is among the leading producers of fresh tomato in Kenya while Kiambu is a major source of kales (sukuma wiki). Nairobi is the main market for the produce and was, therefore, used for studying consumers.

\subsection{Research Design}

The study adopted a mixed methods approach comprising of descriptive survey design and experimental design. Mixed methods research allowed for the collection, analyses and integration of both quantitative (experiments, surveys) and qualitative (focus groups, interviews) data. The descriptive design described the state of affairs as it exists at present. Experimentation, on the other hand, provided a procedure for testing the relationship between independent and dependent variables.

\subsection{Sampling Procedure and Technique}

Select target markets in Nairobi and farms in Kirinyaga and Kiambu were used in the chemical residue study. A random sample was selected from the sampling frame to give each market and farm an equal probability of being selected. Vegetables were randomly purchased from the major vegetable market outlets identified in Nairobi. The target markets were Wakulima as well as major self-service stores in Westlands such as Tuskys, Carry Four, Chandarana and Naivas. Samples for chemical residue estimation and testing from producers were identified during the producer survey.

\subsection{Preparation for Chemical Analysis}

Each sample was a three replicate of a composite sample gathered through random sampling. All the samples (1 to $2 \mathrm{~kg}$ each) were freeze-dried to prevent further physiological change and stored in an ice chess box, to minimize contamination, labeled, and transported to the laboratory for processing and testing. The samples were tested for pesticide and fungicide residues.

\subsection{Sample Extraction and Cleanup}

The QuEChERS sample preparation method for the analysis of chemical residue was used for all the samples. A10 g ration of the standardized sample was weighed up into a $50 \mathrm{~mL}$ polytetrafluoroethylene (PTFE) tube added $10 \mathrm{~mL}$ of acetonitrile. Then, $4 \mathrm{~g}$ magnesium sulphate $\left(\mathrm{MgSO}_{4}\right), 1 \mathrm{~g}$ sodium chloride $(\mathrm{NaCl}), 1 \mathrm{~g}$ sodium citrate tribasic dehydrate $\left(\mathrm{Na}_{3} \mathrm{C}_{6} \mathrm{H}_{5} \mathrm{O}_{7} .2 \mathrm{H}_{2} \mathrm{O}\right)$ and $0.5 \mathrm{~g}$ sodium citrate dibasic sesquihydrate $\left(\mathrm{C}_{6} \mathrm{H}_{5} \mathrm{Na}_{2} \mathrm{O}\right.$. $\left..1 .5 \mathrm{H}_{2} \mathrm{O}\right)$ was added, then samples were shaken thoroughly for $1 \mathrm{~min}$ on a vortex. Samples were centrifuged at $1100 \times \mathrm{g}$ for $5 \mathrm{~min}$. The supernatant $(6 \mathrm{~mL}) \mathrm{was}$ moved to a $15 \mathrm{ml}$ PTFE tube and $900 \mathrm{mg} \mathrm{MgSO} 4,150 \mathrm{mg}$ PSA (Primary and secondary amine) and $150 \mathrm{mg}$ GCB (Graphitized Carbon Black) were put. The extracts were shaken using a vortex mixer for $30 \mathrm{~s}$ then centrifuged at $1100 \times \mathrm{g}$ again for $5 \mathrm{~min}$. Aliquot, $2 \mathrm{~mL}$ of the supernatant placed into a graduated test tube and $20 \mu \mathrm{L}$ of formic acid (HCOOH) were added to adjust the $\mathrm{pH}$. These extracts evaporated to dryness under a stream of nitrogen then reconstructed with 2 $\mathrm{mL}$ of hexane : acetone (4:1) and were then transferred to $2 \mathrm{~mL}$ vial and sealed for quantification by way of gas chromatograph prepared with mass spectrometry (GC-MS).

\subsection{Preparation of Pesticide Standard Solution}

The chemicals were procured from Government Chemist (Nairobi, Kenya) where laboratory analysis of the sample was done. Standard solutions of the chemical were prepared by weighing precisely $10 \mathrm{mg}$ of each chemical into $10 \mathrm{~mL}$ volumetric hipflask and liquefied with acetone; yielding a concentration of $1 \mathrm{mg} / \mathrm{ml}$. mixed solutions of chemical were prepared in $5 \mu \mathrm{g} / \mathrm{mL}$ hexane: acetone (4:1). The standard chemical solutions were prepared at $0.005,0.1,0.25,0.5$ and $1.0 \mu \mathrm{g} / \mathrm{mL}$ concentrations by serial dilution method for making the calibration curve.

\subsection{Instrumental Method}

Chromatographic instrumentation and quantification was done by Gas chromatograph- mass spectrometer GC-MS (Shimadzu QP2010 Ultra) with a GC column HP- 5MS 5\% phenyl-95\% methyl siloxane, $30 \times 0.25 \mathrm{~mm}$ id $\times 0.25$ film thickness. The GC conditions: split less injection, injector temperature $250{ }^{\circ} \mathrm{C}$, helium carrier gas $(99.9999$ purity) at flow rate $1.20 \mathrm{~mL} \mathrm{~min}^{-1}$ with column head pressure $89.4 \mathrm{kpa}$, oven temperature from $100^{\circ} \mathrm{C}(1 \mathrm{~min}$ hold $)$, elevated to 200 ${ }^{\circ} \mathrm{C}$ with a degree of $10{ }^{\circ} \mathrm{C}$ ( 2 min hold) then thereafter raised to $300{ }^{\circ} \mathrm{C}$ degree of $10{ }^{\circ} \mathrm{C}$ (5 min hold). The MS systems were regularly set-in careful ion monitoring (SIM) mode and each composite remained quantitated as per the peak area by use of one target and one or two qualifier ion. 


\subsection{Survey, interviews and focused group discussion}

Sample size was determined based of on the method adopted Delice (2002). Therefore, a total of 384 households in the three counties (Nairobi, Kirinyaga and Kiambu) were interviewed. Data was collected on the socio-demographic profiles, training, popularity of the agrochemicals used, effect of the agrochemicals used and reasons resulting to the effects.

\subsection{Data Analysis}

Data were analyzed using SPSS (v20) for frequency distribution, percentage, mean, and standard deviation.

\section{RESULTS AND DISCUSSION}

\subsection{Chemical residues}

Results from the farm and traded vegetables indicated the presence of various agrochemicals that were either banned or whose controlled use was flouted. These were permethrin, bifenthrin, Malathion, diazinon, carbofuran, carbaryl, cypermethrin, chlorpyrifos, carbendazim, chlorothalonil, mancozeb, and metalaxyl (Table 1). However, mancozeb and metalaxyl were not present on sampled kales. This could attribute to the fact they these fungicides are not used on kales. Mancozeb and metalaxyl (ridomil) is reported to be used in tomato farming to control early and late blights (Kariathi et al., 2016), thus explaining its presence on tomatoes. Previous studies such as Lozowicka et al. (2015) detected similar residues, particularly, chlorothalonil, metalaxyl, bifenthrin and endosulfan in tomatoes. Jara \& Winter (2019) also observed high levels of organophosphates of vegetables. More than two thirds of tomato samples returned residue levels for alpha, beta sulphate and total endosulfans that exceeded permitted limits at the national customs and the European Union (EU) markets (Ibid). Closer home, a study by Kiwango et al. (2018) in Tanzania detected residues of permethrin, chlorpyrifos and ridomil (metalaxyl and mancozeb) at levels that could compromise the consumer's health. Inonda et al. (2015) also observed that pesticide residues were common on vegetables especially during the hot/dry season and were mainly organophosphates. In all the examples, deviations were blamed on farmers' spraying pesticides too close to the harvest and the habit of mixing-up pesticides of different kinds into a single spray for convenience. This was also confirmed by the study where not observing preharvest intervals was found to be a major issue.

Table 1. Chemical residues identified in the farm and market on tomatoes and kales

\begin{tabular}{|c|c|c|c|c|c|c|}
\hline \multirow{2}{*}{ Agrochemical } & \multirow{2}{*}{ Type } & \multirow{2}{*}{ Group } & \multicolumn{2}{|c|}{ Tomatoes } & \multicolumn{2}{|l|}{ Kales } \\
\hline & & & Farm & Market & Farm & Market \\
\hline 1) Permethrin & \multirow{8}{*}{ Insecticide } & \multirow{3}{*}{ Pyrethroid } & $\square$ & $\nabla$ & $\square$ & $\square$ \\
\hline 2) Bifenthrin & & & $\nabla$ & $\nabla$ & $\nabla$ & $\nabla$ \\
\hline 3) Cypermethrin & & & $\nabla$ & $\nabla$ & $\nabla$ & $\nabla$ \\
\hline 4) Malathion & & \multirow{3}{*}{ Organophosphate } & $\nabla$ & $\nabla$ & $\nabla$ & $\nabla$ \\
\hline 5) Diazinon & & & $\nabla$ & $\nabla$ & $\nabla$ & $\nabla$ \\
\hline 6) Chlorpyrifos & & & $\nabla$ & $\nabla$ & $\nabla$ & $\nabla$ \\
\hline 7) Carbaryl & & \multirow{2}{*}{ Carbamate } & $\nabla$ & $\bar{\nabla}$ & $\bar{\nabla}$ & $\bar{\nabla}$ \\
\hline 8) Carbofuran & & & $\nabla$ & $\bar{\nabla}$ & $\nabla$ & $\nabla$ \\
\hline 9) Carbendazim & \multirow{4}{*}{ Fungicide } & Benzimidazole & $\nabla$ & $\nabla$ & $\nabla$ & $\nabla$ \\
\hline 10) Chlorothalonil & & Organic & $\nabla$ & $\bar{\nabla}$ & $\nabla$ & $\nabla$ \\
\hline 11) Mancozeb & & Dithiocarbamate & $\nabla$ & $\nabla$ & 冈 & 冈 \\
\hline 12) Metalaxyl-M & & Acylalanine & $\nabla$ & $\nabla$ & 冈 & 冈 \\
\hline
\end{tabular}

\subsection{Socio-demographic profiles}

The study established that $46.4 \%$ of the participants were female while $53.6 \%$ of the respondents were male (Table 2 ). From the interviews, farmers explained that more men than women owned land, capital and other key assets of production including the know-how. This could explain the narrow difference in the participation of women in commercializing vegetables. Other studies in East Africa such as Kiriathi et al. (2016) have found more women participating in vegetable commercialization reason being that the men have to go to urban areas to do formal jobs for which women are less equipped. Nonetheless, gender disparity in Kenya is a major problem regarding farming. The study revealed that vegetable farming and commercialization increased with age of the respondents (Table 2). Respondents increased with increase on age. Majority of the respondents $(83.9 \%)$ were over 33 years, followed by respondents between 28 to 32 years $(12.8 \%)$ and between 23 to 37 years (3.3\%), while none was between 18 to 32 years. Majority $(63.8 \%)$ of the respondents were married while only $36.2 \%$ of the respondents were single. Based on education, $38.9 \%$ of the respondents had attained secondary (high school) education level, $26.9 \%$ had attained primary education, $26.2 \%$ had attained college/university education while only $8 \%$ had no education. A lack of education contributes to the abuse of agrochemicals (Kiriathi et al., 2016), particularly, overdosing, mixing-up pesticides, repeated applications and spraying close to harvests. An accurate interpretation of pesticide labels (which is often in English) and also outlines 
personal safety procedures, is untenable without a basic education. Information literacy is therefore is therefore important for greater adoption of best practices leading to food and personal safety. This could have a ripple-effect including but not limited to greater market access, household revenues and more education for farming communities.

Table 2. Socio-demographic profiles of vegetable farmers in the study area $(n=384)$

\begin{tabular}{lllc}
\hline & & \multicolumn{2}{c}{ Respondents } \\
\hline Variable & Categories & n & \% \\
\hline \multirow{2}{*}{ Sex } & $\mathrm{F}$ & 178 & 46.4 \\
& $\mathrm{M}$ & 206 & 53.6 \\
\multirow{4}{*}{ Age } & $18-22$ & 0 & 0.0 \\
& $23-27$ & 13 & 3.3 \\
\multirow{3}{*}{ Marital Status } & $28-32$ & 49 & 12.8 \\
& +33 & 322 & 83.9 \\
\multirow{2}{*}{ Education } & Single & 139 & 36.2 \\
& Married & 245 & 63.8 \\
& College/ university & 100 & 26.2 \\
Economic Activity & Secondary & 149 & 38.9 \\
& Primary & 103 & 26.9 \\
& None & 32 & 8.0 \\
& Crop Farmer & 337 & 87.9 \\
\hline
\end{tabular}

\subsection{Training}

Based on training, majority of respondents in Kirinyaga (33.5\%) and Kiambu (35.1\%) had not attended any training concerning agrochemical use and food safety. However, in Nairobi County, majority of farmers had attended training on either agrochemical use $(29.2 \%)$ or food safety $(30.2 \%)$. The lowest number was that of respondents who had attended both training on agrochemical use and food safety in Nairobi (15.8\%), Kirinyaga (15.3\%), and Kiambu (10.4\%) counties (Figure 1). According to the farmers interviewed, these trainings were organized by dealers of specific agrochemicals as promotions for single products. This could explain why the training was only geared towards single objectives rather than be multi-faceted. Nyamari et al. (2014) also reported that training can improve knowledge on matters food safety. The results of this study support the assumption that training on food safety and agrochemical use would help producers and consumers to use best practices to reduce agrochemical residue and food contamination. However, most of the producers of tomatoes and kales are small-scale farmers who are resource limited and may not afford fees to pay for trainings on agrochemical use and food safety and only rely on government support or donors for such trainings. This explains why there was limited trainings on food safety and/or agrochemical use, particularly in Kiambu and Kirinyaga counties.

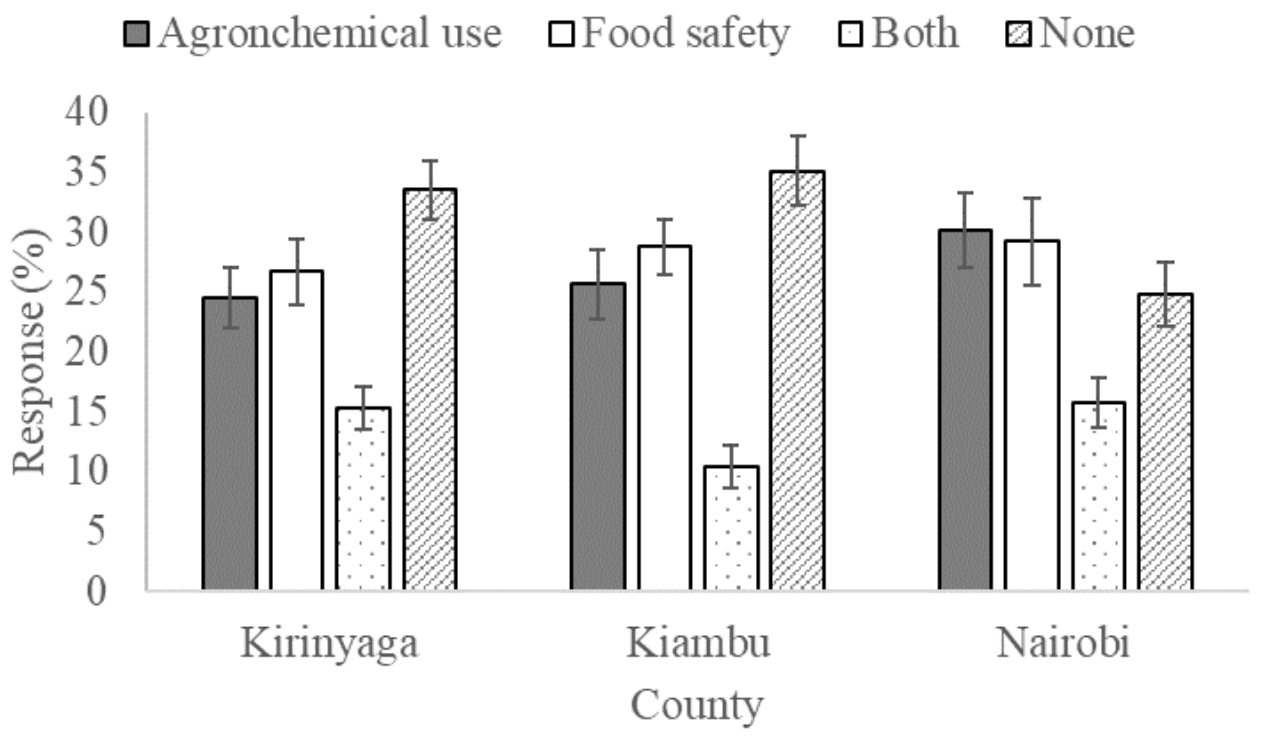

Figure 1. Number of respondents who attended training on agrochemical use and food safety. Bars represent means \pm standard deviations. 


\subsection{Popularity of agrochemicals}

Most of the respondents indicated that the agrochemicals were popular for use by farmers (Figure 2). The most common agrochemical was carbofuran $(67 \%)$ in terms of insecticide. Some respondents also indicated pesticides like diazinon $(52 \%)$, cypermethrin $(50 \%)$, carbaryl $(48 \%)$, bifenthrin $(45 \%)$, chlorpyrifos $(45 \%)$, malathion $(41 \%)$, and permethrin $(40 \%)$, in the order of popularity. For the case of fungicides, the most common was mancozeb (60\%) and metalaxyl (58\%). Others also indicated chlorothalonil (43\%) and carbendazim (50\%). The popularity of pesticides among farmers explained, the popularity of certain pesticides was related to information of successful application from peers, their affordability and their availability within local agro vet shops. The study finds that farmer characteristics crucial to vegetable commercialization were also important in predicting the intensity of agrochemical use and perhaps compromise ethics. Some insecticides like carbofuran is an N-methyl-carbamate insecticide/nematicide that inhibits acetylcholinesterase (AChE) and has been in use for over 40 year's world over as a systemic insecticide to control both soil-dwelling and leaf-eating insects (Gammon et al., 2012). In tomato, carbofuran is used to control white flies (Bemisia tabaci) a key vector of the dreaded Tomato Yellow Leaf Curl Virus (TYLCV) disease (Anandkumar and Hemalatha, 2018). During treatment, the insecticide is applied as either granules around the base or as a concentrate sprayed onto the leaves (Gammon et al., 2012).

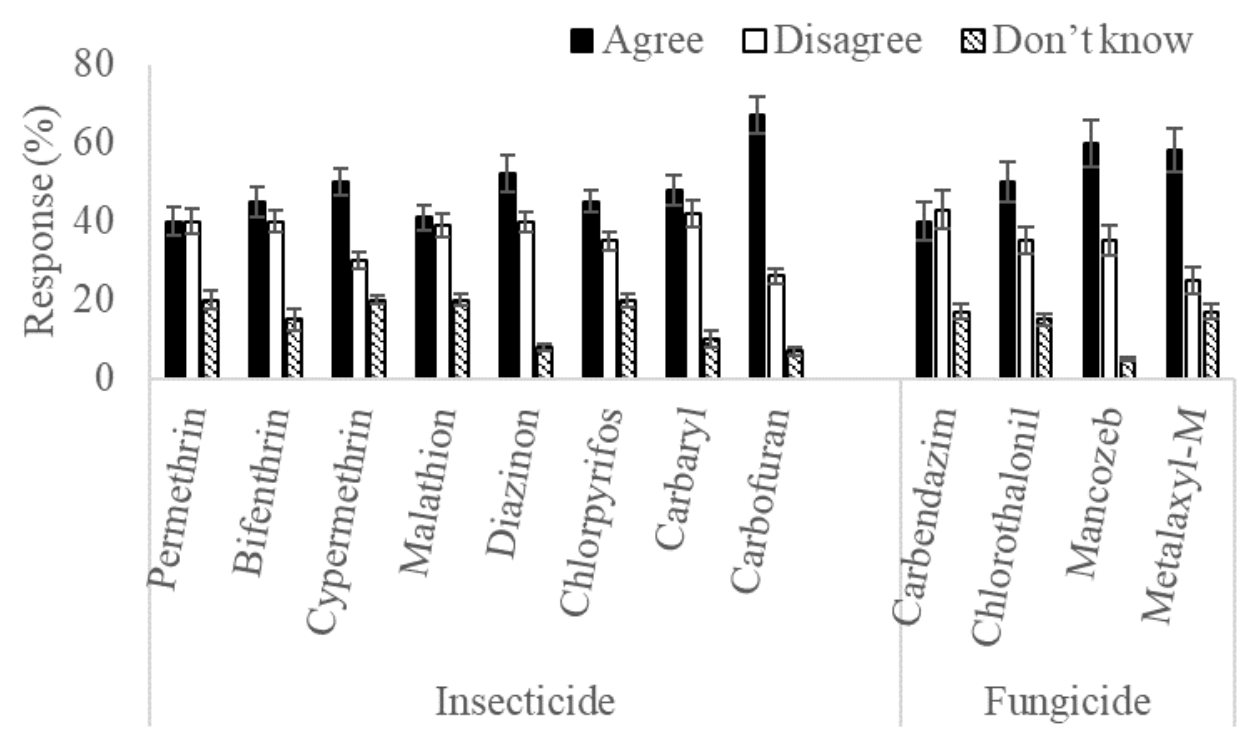

Figure 2. Popularity of agrochemicals among the respondents. Bars represent means \pm standard deviations.

\subsection{Causes of chemical residues}

Based on causes of food toxicity regarding agrochemical use, majority of respondents in Kirinyaga (55\%), Nairobi (58\%) and Kiambu (65\%) reported that food safety is caused by not observing preharvest intervals. Others indicated excessive application of chemicals while some indicated the use of illegal agrochemicals (Figure 3). Farmers in Kiambu and Kirinyaga overdosed pesticides reasoning that by exceeding the prescriptions on the label enhanced efficacy. This sentiment is often due to farmers' over-estimation of pest pressure and impact (Hou \& Wu, 2010). Additionally, farmers in Kirinyaga resorted to overdosing permitted pesticides or using banned pesticides such as Malathion to repel wildlife from the nearby Aberdare National Park. This application of pesticides to combat wildlife depredation and crop damage is also widely acknowledged (Njoku et al., 2017). Vegetables like kales and tomatoes are also on demand among the consumers. However, in order produce substantial yield, farmers resort to excessive application of pesticides to control various pests in these crops. For effective management of these pests, some farmers go to the extent of using banned agrochemicals like dimethoate available in the black markets (Mutuku et al., 2014).

Small-scale farmers often grow tomatoes and kales in hardship or unplanned areas without the requisite advice by extension officers. As a result, farmers are vulnerable to outbreaks of pests, pesticide resistance and poor choice or application of pesticides all of which encouraged them to abuse pesticide application protocols. In their research of the red spider mite (Tetranychus evansi) infestation in key tomato growing hotspots in Kenya (Loitoktok, Kibwezi, AthiRiver and Subukia), Toroitich et al. (2014) demonstrated how initial application of dimethoate on tomato reduced the efficacy of subsequent pesticides including bifenthrin, lambdacyhalothrin, dicofol, propargite and a mixture of profenofos and cypermethrin. In their opinion, prior applications resulted from lack of awareness, carelessness or accidents. However, farmers responded using illegal chemicals or unorthodox mixing and overdosing of available 
pesticides. Both of these practices were more prevalent among smaller farmers who, unlike their wealthy large-scale counterparts, could afford pest control expertise. Nonetheless, there was other compelling evidence in favour of the correlation that seemed to counter the notion of accidents and carelessness among small farmers. It portrayed large-scale farmers as being heavily pesticide-dependent given the sensitive nature of the crops they farmed and the strict market requirements they responded to (Toroitich et al., 2014). Inonda et al. (2015) also noted that adherence to recommended preharvest intervals resulted in $99 \%$ reduction of the pesticide residues, demonstrating that not observing preharvest intervals is a serious problem in vegetable farmers (kales and French beans).

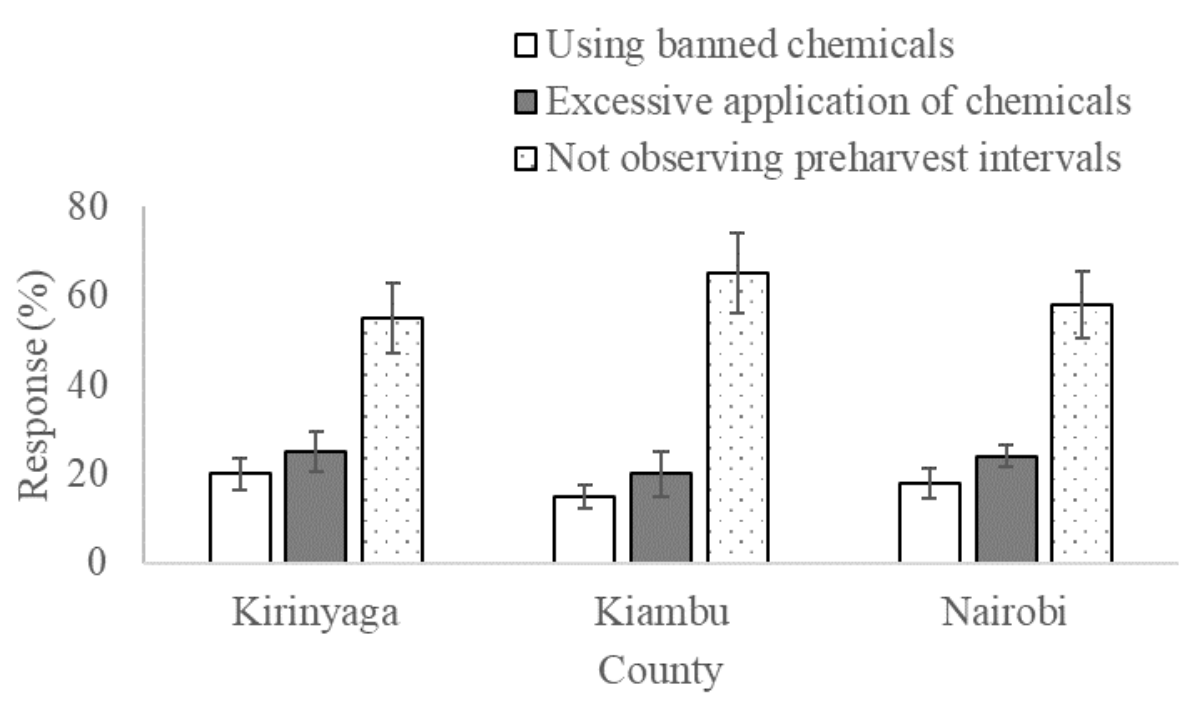

Figure 3. Main causes of chemical residues. Bars represent means \pm standard deviations.

\subsection{Effects of misuse of agrochemicals}

Regarding effect of misuse of agrochemicals, majority of the respondents in Kirinyaga (49\%), Nairobi (48\%) and Kiambu (43\%) reported that it results in carcinogenic diseases. Others reported that it causes stomach related problems (15 to $19 \%$ ), eye related problems (10 to $15 \%)$, and skin related problems (11 to $14 \%$ ) and breathing difficulties (10 to 12\%) (Figure 4). There is, therefore, a heightened sense of awareness along the vegetable value-chains that pesticide contamination is hazardous. Amongst small-scale farmers, as was the case in Kirinyaga, awareness of pesticide misuse was also tied with their overestimation of the impacts of pest-damage. This is not a new finding and had already been documented in China (Hou \& Wu, 2010). In human, carbofuran has been shown to be extremely toxic manifesting skin and later on, neurological effects (Ibid). The chemical has been shown to have more profound effects on wildlife, particularly birds, scavengers and predators such as lions and hyenas (Otieno et al., 2011). Matter of fact, the chemical drew tremendous publicity in Kenyan media as farmers bordering national parks and game reserves in which farmers applied it in baits targeting predators as retaliation against depredation (Ibid). Mancozeb and metalaxyl were often in use among small-scale farmers growing tomatoes, least among small-scale farmers growing kales. The results agree with those of Fatma, et al. (2018) who noted that mancozeb and chlorpyrifos have been proved to be effective in the reproduction in large scale system including and not limited to increasing vegetable production and these pesticides have recorded environmental persistence are highly toxic towards aquatic ecosystem including fish. De Silva et al. (2010) add that these pesticides are also toxic to pollinators such as bees and have been associated with reduced bee populations. Statistics on residual levels of mancozeb in Kenya are still limited but grey studies from elsewhere such as Chile (Elgueta et al., 2020) and Uganda (Atuhaire et al., 2017; Kaye et al., 2015) have shown residue levels to be as much as seven times the prescribed levels. Sadly, mancozeb is a known carcinogen in rats and can cause Parkinsons' disease in humans (Ibid). It is assumed that farmers come into greater contact with pesticides during mixing, application and cleaning. However, reports show that ingestion (more prevalent among consumers) far outweighed inhalation and skin contact (more prevalent for farmers) for pesticide intakes in the human body. Gammon et al. (2012) observed that dermal exposures to carbofuran took 12 times longer to manifest impacts on brain activity (Acetycholiesterase inhibition) in lab rats compared to ingesting similar quantities. 


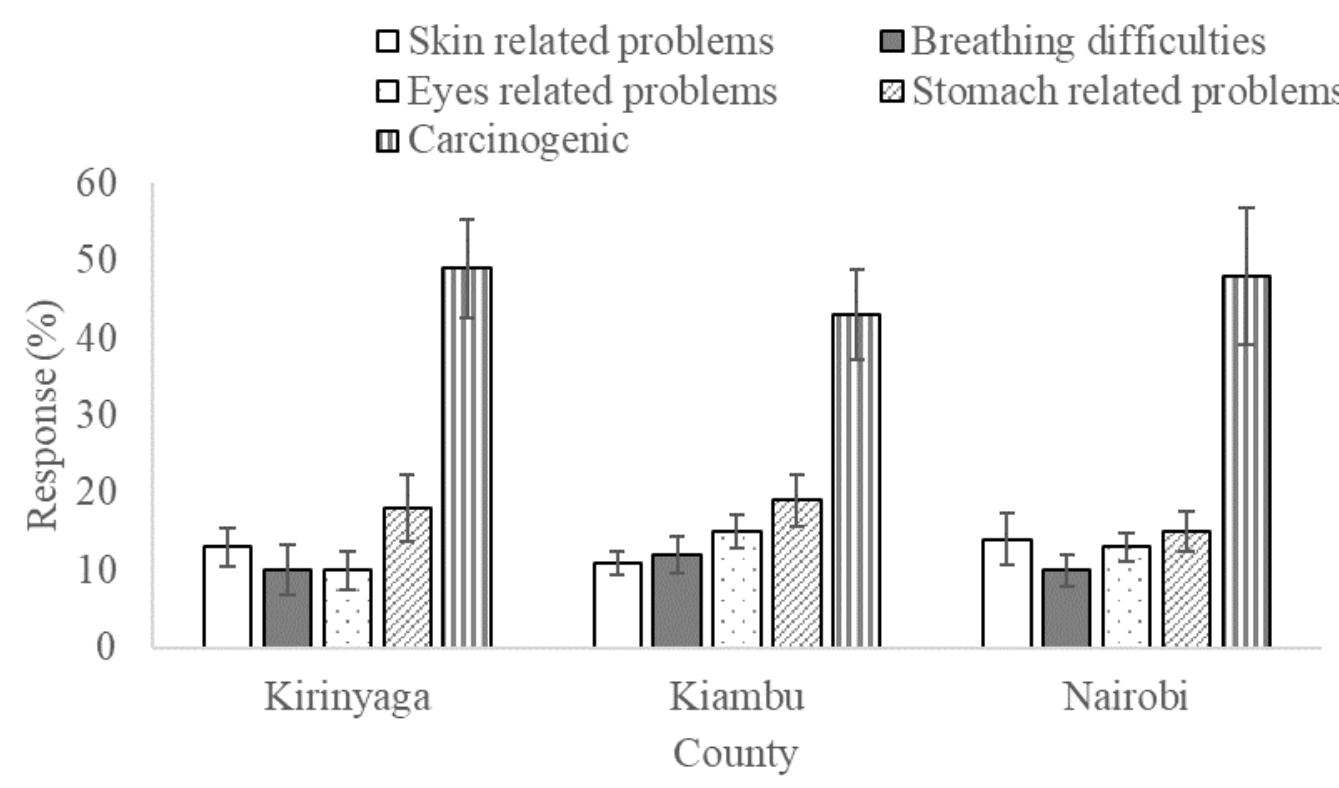

Figure 4. Effect of misuse of agrochemicals. Bars represent means \pm standard deviations.

\section{CONCLUSION AND RECOMMENDATION}

The present study chemical residues are a major problem in kale and tomato value chain in Kiambu, Kirinyaga and Nairobi county, resulting in food safety concerns. The major problems of food safety and agrochemical use were attributed to low levels of education (38.9\%) and lack of training (33.1 to 35.1\%). The most common agrochemical was carbofuran $(67 \%)$ in terms and insecticide. For the case of fungicides, the most common was mancozeb (60\%) and metalaxyl (58\%). Food safety issues are caused by mainly not observing preharvest intervals, excessive application of chemicals and use of illegal agrochemicals. Chemical residues in food mainly results in carcinogenic diseases (43 to $49 \%$ ), stomach related problems (15 to $19 \%$ ), eye related problems (10 to $15 \%)$, and skin related problems (11 to $14 \%)$ and breathing difficulties (10 to 12\%). This study demonstrates that there is a problem of agrochemical use and food safety concerns and kale and tomato value chain. Therefore, there is need for the awareness creation and law enforcement on agrochemical use and food safety along the kale and tomato value chain. Further on, the study urges collaborative studies amongst agronomists and wildlife managers in assessing the extent of pesticide use in combating problematic wildlife. Relevant government authorities are encouraged to adopt the use of Swahili in the development and printing of agrochemical labels for easy communication with the farmers and general public, majority of whom do not understand the very technical language currently used.

\section{ACKNOWLEDGMENT}

The work forms part of the requirements for the doctor of philosophy degree of Pwani University.

\section{REFERENCES}

Agudo, A., Cabrera, L., Amiano, P., Ardanaz, E., Barricarte, A., Berenguer, T., ... Larranaga, N. (2007). Fruit and vegetable intakes, dietary antioxidant nutrients, and total mortality in Spanish adults: Findings from the Spanish cohort of the European Prospective Investigation into Cancer and Nutrition (EPIC-Spain). The American Journal of Clinical Nutrition, 85(6), 1634-1642.

Ahoudi, H., Gnandi, K., Tanouayi, G., Ouro-Sama, K., Yorke, J-C, Creppy, E.E., \& Moesch, C. (2018). Assessment of pesticides residues contents in the vegetables cultivated in urban area of Lome (southern Togo) and their risks on public health and the environment, Togo. International Journal of Biological Chemical Sciences, 12(5), 2172-2185.

Atuhaire, A., Kaye, E., Mutambuze, I. L., Matthews, G., Friedrich, T., \& Jørs, E. (2017). Assessment of dithiocarbamate residues on tomatoes conventionally grown in Uganda and the effect of simple washing to reduce exposure risk to consumers. Environmental Health Insights, 11, 1178630217712218.

D’Alessandro, S. P., Caballero, J., Lichte, J., \& Simpkin, S. (2015). Agricultural Sector Risk Assessment (Report Number 97887; p. 138).

De Silva, P.M.C., Pathiratne, A., \& van Gestel, C.A. (2010). Toxicity of chlorpyrifos, carbofuran, mancozeb and their formulations to the tropical earthworm Perionyx excavatus. Applied Soil Ecology, 44(1), 56-60. 
Elgueta, S., Valenzuela, M., Fuentes, M., Meza, P., Manzur, J. P., Liu, S., ... \& Correa, A. (2020). Pesticide residues and health risk assessment in tomatoes and lettuces from farms of Metropolitan Region Chile. Molecules, 25 (2), 355.

Fatma, F., Verma, S., Kamal, A., \& Srivastava, A. (2018). Phytotoxicity of pesticides mancozeb and chlorpyrifos: correlation with the antioxidative defence system in Allium cepa. Physiology and Molecular Biology of Plants, 24(1), 115-123.

Gammon, D.W., Liu, Z. and Becker, J.M. (2012). Carbofuran occupational dermal toxicity, exposure and risk assessment. Pest Management Science, 68, 362-370.

Gitonga, K.J., Gathambiri, C., Kamau, M., Njuguna, K., Muchui, M., Gatambia, E., \& Kiiru, S. (2010). Enhancing small scale farmers' income in mango production through agro-processing and improved access to markets. Transforming Agriculture for Improved Livelihoods through Agricultural Product Value Chains. Proceedings of the 12th KARI Biennial Scientific Conference, Kenya Agricultural Research Institute, Nairobi, Kenya, 13361342 .

Hou, B. \& Wu, L. (2010). Safety impact and farmer awareness of pesticide residues. Food and Agricultural Immunology, 21(3), 191-200.

Inonda, R., Njage E., Ngeranwa, J., \& Mutai, C. (2015). Determination of pesticide residues in locally consumed vegetables in Kenya. African Journal of Pharmacology and Therapeutics, 4(1), 1-6.

Jara, A.E. \& Winter, C.K. (2019). Safety levels for organophosphate pesticide residues on fruits, vegetables, and nuts. International Journal of Food Contamination, 6(6), 1-8.

Kaye, E., Nyombi, A., Mutambuze, I.L., \& Muwesa, R. (2015). Mancozeb residue on tomatoes in Central Uganda. Journal of Health Pollution, 5(8), 1-6.

Kenmore, P.E., Stannard, C., \& Thompson, P.B. (2004). The ethics of sustainable agricultural intensification (Vol. 4). FAO, Rome.

Kariathi, V., Kassim, N., Kimanya, M. (2016). Pesticide exposure from fresh tomatoes and its relationship with pesticide application practices in Meru district. Cogent Food and Agriculture, 2, 1-12.

Kiwango, P.A., Kassim, N. \& Kimanya, M.E. (2018). Pesticide residues in vegetables: practical interventions to minimize the risk of human exposure in Tanzania. Current Journal of Applied Science and Technology, 26(1), $1-18$.

Lozowicka, B., Abzeitova, E., Sagitov, A., Kaczynski, P., Toleubayev, K., \& Li, A. (2015). Studies of pesticide residues in tomatoes and cucumbers from Kazakhstan and the associated health risks. Environmental Monitoring and Assessment, 187, 609.

Mabe, F. N., Talabi, K., \& Danso-Abbeam, G. (2017). Awareness of health implications of agrochemical use: Effects on maize production in Ejura-Sekyedumase municipality, Ghana. Advances in Agriculture, 2017, 1-11.

Muriithi, B. W., \& Matz, J. A. (2015). Welfare effects of vegetable commercialization: Evidence from smallholder producers in Kenya. Food Policy, 50, 80-91

Mutuku, M., Njogu, P., \& Nyagah, G. (2014). Assessment of pesticide use and application practices in tomato based agrosystems in Kaliluni sub location, Kathiani District, Kenya. Journal of Agriculture, Science and Technology, $16(2), 34-44$.

Nguetti, J. H., Imungi, J. K., Okoth, M. W., Wang’ombe, J., Mbacham, W. F., \& Mitema, S. E. (2018). Assessment of the knowledge and use of pesticides by the tomato farmers in Mwea Region, Kenya. African Journal of Agricultural Research, 13(8), 379-388.

Nicklett, E. J., Semba, R. D., Xue, Q.-L., Tian, J., Sun, K., Cappola, A. R., ... Fried, L. P. (2012). Fruit and vegetable intake, physical activity, and mortality in older community-dwelling women. Journal of the American Geriatrics Society, 60(5), 862-868.

Njoku, K.L., Ezeh, C.V., Obidi, F.O. \& Akinola, M.O. (2017). Assessment of pesticide residue levels in vegetables sold in some Markets in Lagos State, Nigeria. Nigerian Journal of Biotechnology, 32, 53-60.

Nyamari, J., Mugendi, B., Keraka M., \& Agwata, D. (2014). Effectiveness of Food Safety Training on Food Safety Knowledge and Practices of Hospital Food Handlers in Selected Hospitals in Kenya. Elite Research Journal of Food Science and Nutrition, 1(1), 12-21.

Okado, M. (2001). Background Paper on Kenya off-season and specialty fresh fruits and vegetables: Lessons of experience from the Kenya horticultural industry. United Nations Conference on Trade and Development Regional Workshop for Horticultural Economies in Africa. Nairobi, Kenya.

Okello, J. J., \& Swinton, S. M. (2010). From Circle of Poison to Circle of Virtue: Pesticides, Export Standards and Kenya's Green Bean Farmers. Journal of Agricultural Economics, 61(2), 209-224.

Otieno, P.O., J.O. Lalah, M. Virani, I.O. Jondiko \& K.W. Schramm. 2011. Carbofuran and its toxic metabolites provide forensic evidence for Furadan exposure in vultures (Gyps africanus) in Kenya. Bulletin of Environmental Contamination and Toxicology, 84, 536-544.

Oyebode, O., Gordon-Dseagu, V., Walker, A., \& Mindell, J.S. (2014). Fruit and vegetable consumption and all-cause, cancer and CVD mortality: Analysis of Health Survey for England data. Journal of Epidemiology and Community Health, 68(9), 856-862. 
Oyugi, R.B. (2013). Pesticide residues in some vegetables rotated with tobacco using HPLC, and farmers' awareness of pesticide health effects in Kuria- Migori, Kenya (Thesis, Kenyatta University). Retrieved from https://irlibrary.ku.ac.ke/handle/123456789/6546

Prabhakar, S., Sano, D and Srivastava, N. (2010). Food Safety in the Asia-Pacific Region: Current Status, Policy Perspectives and a Way Forward. In Sustainable Consumption and Production in the Asia-Pacific Region: Effective Responses in a Resource Constrained World, Institute for Global Environmental Strategies, White Paper III, pp 215-238. Institute for Global Environmental Strategies, Hayama, Japan.

Rahman, S., Mele, M.A., Lee, Y.-T., \& Islam, M.Z. (2021). Consumer preference, quality, and safety of organic and conventional fresh fruits, vegetables, and cereals. Foods, 10(105), 1-17.

Schneider, M., Norman, R., Steyn, N and Bradshaw, D. (2007). Estimating the burden of disease attributable to low fruit and vegetable intake in South Africa in 2000. South Africa Medical Journal, 97(8):717-23.

Tilman, D., Balzer, C., Hill, J., \& Befort, B. L. (2011). Global food demand and the sustainable intensification of agriculture. Proceedings of the National Academy of Sciences, 108(50), 20260-20264.

Toroitich, F. J., Knapp, M., Nderitu, J. H., Olubayo, F. M., \& Obonyo, M. (2014). Susceptibility of geographically isolated populations of the Tomato red spider mite (Tetranychus evansi Baker \& Pritchard) to commonly used acaricides on tomato crops in Kenya. Journal of Entomological and Acarological Research, 46(1), 18-25.

Trichopoulou, A., Costacou, T., Bamia, C., \& Trichopoulos, D. (2003). Adherence to a Mediterranean diet and survival in a Greek population. The New England Journal of Medicine, 348(26), 2599-2608.

Unnevehr, L.J. (2000). Food safety issues and fresh food product exports from LDCs. Agricultural Economics, 23(3), 231-240.

Waltner-Toews, D., \& Lang, T. (2000). A new conceptual base for food and agricultural policy: The emerging model of links between agriculture, food, health, environment and society. Global Change and Human Health, 1(2), 116130 .

WHO. (2014). Food safety. Fact sheet N0. 399 [Informational]. Retrieved from World Health Organization Fact sheets website: https://www.who.int/news-room/fact-sheets/detail/food-safety 